\title{
Some Diptera newly recorded from Ukraine
}

\author{
Jozef Oboňa, Libor Dvořák, Peter Manko, Ruslan Mariychuk, \\ Jaroslav Starý \& Michal Tkoč
}

Some Diptera newly recorded from Ukraine. - Acta Mus. Siles. Sci. Natur., 66: 41-48, 2017.

\begin{abstract}
Results of faunistic research of eight selected dipteran families (Bibionidae, Blephariceridae, Dixidae, Limoniidae, Pediciidae, Platypezidae, Ptychopteridae, and Rhagionidae) in the Uzh River Basin (Ukraine) are presented thanks to the support by the FAN (B) - Förderkreis für allgemeine Naturkunde (Biologie) in the framework of the project "Ephemeroptera, Plecoptera, Diptera biodiversity trip along the Uzh river, Ukraine". Altogether 16 species are recorded as new to the fauna of Ukraine in the present paper. One species is newly recorded of the families Blephariceridae, Pediciidae, and Ptychopteridae, and two species each of the families Limoniidae and Bibionidae. Three species each belong to the families Dixidae, Platypezidae, and Rhagionidae.
\end{abstract}

Key words: Diptera, Bibionidae, Blephariceridae, Dixidae, Limoniidae, Pediciidae, Platypezidae, Ptychopteridae, Rhagionidae, first records, species richness, Ukraine

\section{Introduction}

The fauna of two-winged or true flies (Diptera) of Ukraine is unequally known. Some dipteran families are comparatively well-studied, especially the commonest epidemiologically significant families (e.g. Culicidae, Simuliidae, and Tabanidae), or those with important economic pests (e.g. Cecidomyiidae, Piophilidae, Tephritidae, Ulidiidae). Undoubtedly, much less attention has been devoted to epidemiologically insignificant aquatic Diptera (e.g. Psychodidae, Ptychopteridae, Dixidae, etc). Data on still other families are rather poor. On the other hand, the tipulomorphan families Limoniidae, Pediciidae, and Tipulidae are wellinvestigated in Ukraine although insignificant, or little so, from both epidemiologic and economic points of view.

Ukraine is a highly diversified country with huge potential for various, not only faunistic activities. Especially interesting are natural old forests in the upper part of the Uzh River Basin that may constitute refuges for native species, very rare or missing in many other European countries due to intensive forestry.

\section{Material and methods}

The material presented in this paper was collected along the Uzh River, Ukraine, by J. Oboňa, P. Manko, and R. Mariychuk (viii.2015 and v.2016). Samples were collected by sweep-netting from vegetation along streams and lakes (Tab. 1, Figs 1-3).

Some specimens were dried from ethanol, pinned, or glued onto points, the rest is preserved in $75 \%$ ethanol, all identified and deposited in the collections of the authors or institutional collections under their care.

Blephariceridae, Limoniidae, and Pediciidae were identified by J. Starý using Oosterbroek (2016) and Tuša (1992 a,b); material is deposited in the collection of J. Starý (Olomouc, Czech Republic). Rhagionidae and Bibionidae were identified by L. Dvoř́a using Haarto (2012), Krivosheina (1969) and Rozkošný \& Spitzer (1965); material is deposited in the collection of L. Dvořák (Tři Sekery nr. Mariánské Lázně, Czech Republic). Dixidae and Ptychopteridae were identified by J. Oboňa based on Disney (1999) and Zitek-Zwyrtek (1971); material is deposited in the Laboratory and Museum of Evolutionary Ecology, Department of Ecology, University of Prešov, Slovakia. Platypezidae were identified by M. Tkoč using the key in Chandler (2001) and are deposited in the National Museum in Prague, Czech Republic. 
Tab 1: List of sampling sites.

\begin{tabular}{|l|l|l|l|l|}
\hline Site No. & \multicolumn{1}{|c|}{ Site name (short description of locality) } & \multicolumn{1}{|c|}{ Latitude/ N } & \multicolumn{1}{|c|}{ Longitude/ E } & \multicolumn{1}{c|}{$\begin{array}{c}\text { Altitude/ } \\
\text { m a.s.l. }\end{array}$} \\
\hline 1 & $\begin{array}{l}\text { Shypot River, between hydroelectric power } \\
\text { plants }\end{array}$ & $48^{\circ} 45^{\prime} 13.9^{\prime \prime}$ & $22^{\circ} 51^{\prime} 07.0^{\prime \prime}$ & 380 \\
\hline 2 & Vojevodyn Stream & $48^{\circ} 46^{\prime} 22.3^{\prime \prime}$ & $22^{\circ} 52^{\prime} 30.8^{\prime \prime}$ & 500 \\
\hline 3 & Shypotyk Stream & $48^{\circ} 44^{\prime} 23.4^{\prime \prime}$ & $22^{\circ} 50^{\prime} 17.1^{\prime \prime}$ & 400 \\
\hline 4 & Lyuta River above Chornoholova & $48^{\circ} 51^{\prime} 43.0^{\prime \prime}$ & $22^{\circ} 36^{\prime} 21.8^{\prime \prime}$ & 405 \\
\hline 5 & Kamenychky Stream & $48^{\circ} 48^{\prime} 37.4^{\prime \prime}$ & $22^{\circ} 28^{\prime} 33.3^{\prime \prime}$ & 255 \\
\hline 7 & tributary of the River Uzh, near Sukhyi & $48^{\circ} 58^{\prime} 12.2^{\prime \prime}$ & $22^{\circ} 48^{\prime} 15.1^{\prime \prime}$ & 650 \\
\hline 8 & Paporotnyi Stream & $49^{\circ} 01^{\prime} 41.3^{\prime \prime}$ & $22^{\circ} 35^{\prime} 16.0^{\prime \prime}$ & 580 \\
\hline 10 & Uzh River, above Stuzhytsya & $49^{\circ} 02^{\prime} 26.0^{\prime \prime}$ & $22^{\circ} 34^{\prime} 53.0^{\prime \prime}$ & 590 \\
\hline
\end{tabular}

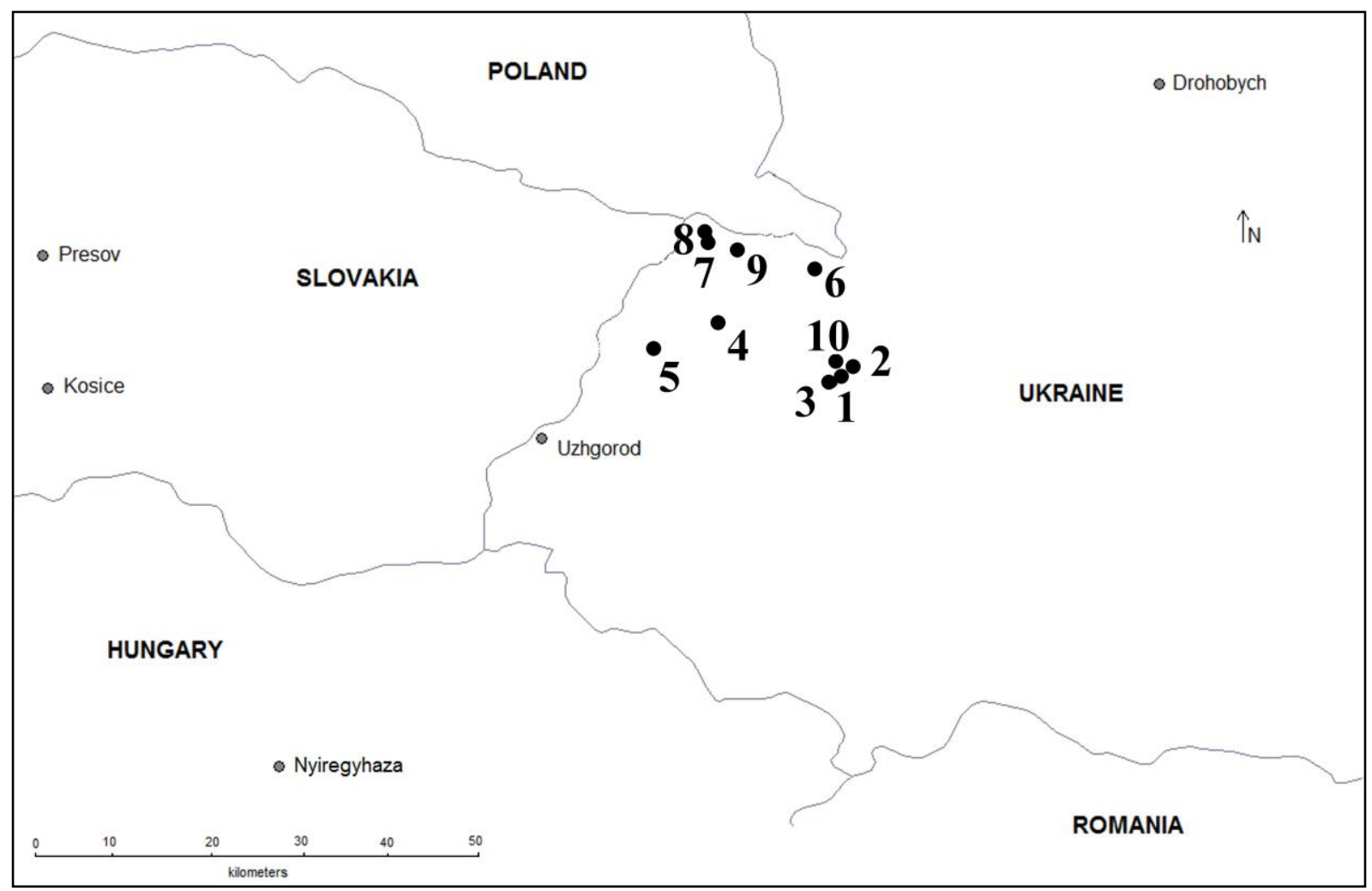

Fig 1: Map showing all sampling sites in Ukraine. 


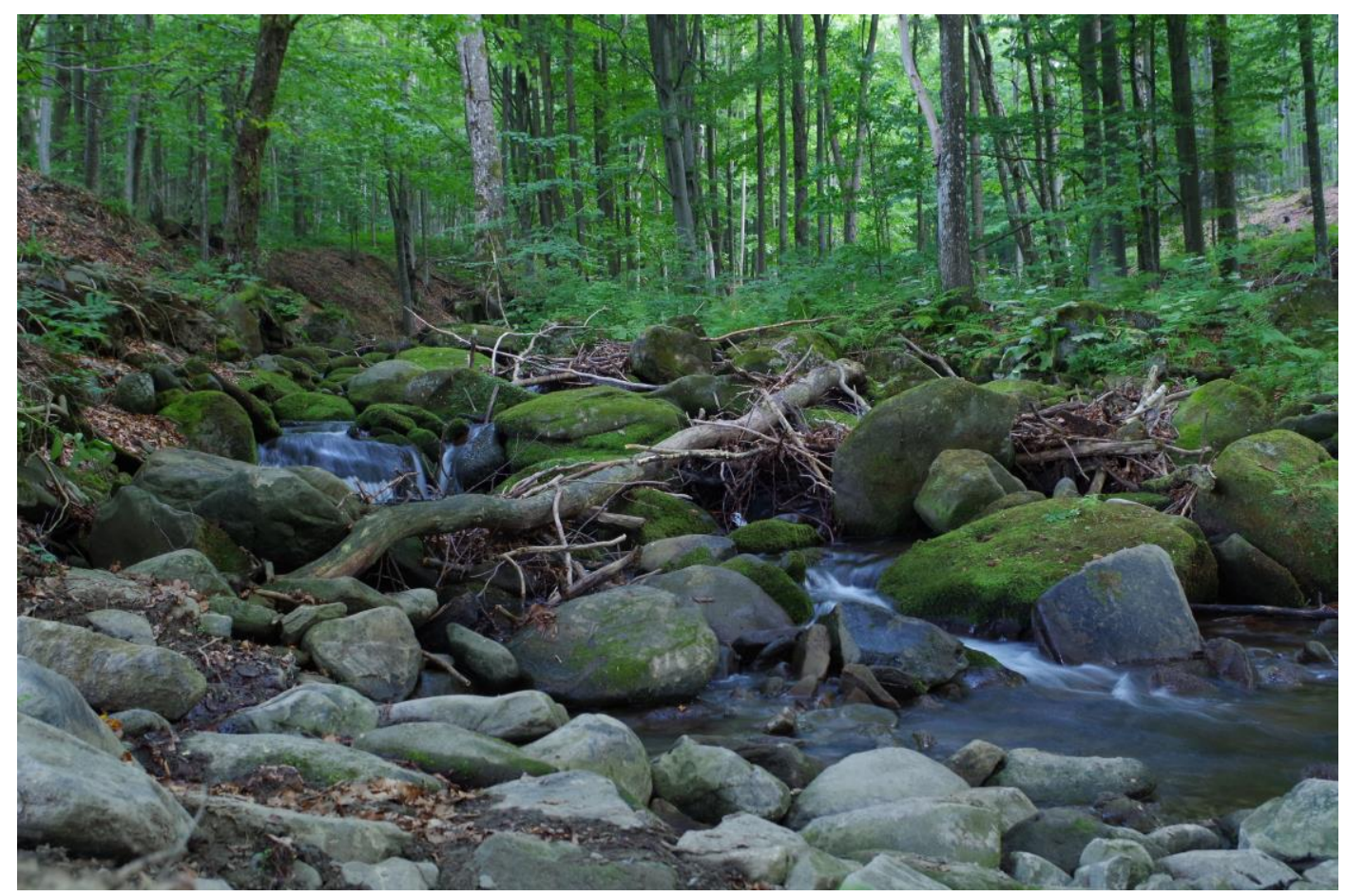

Fig 2: Sampling site No. 1: Shypot River, between hydroelectric power plants.

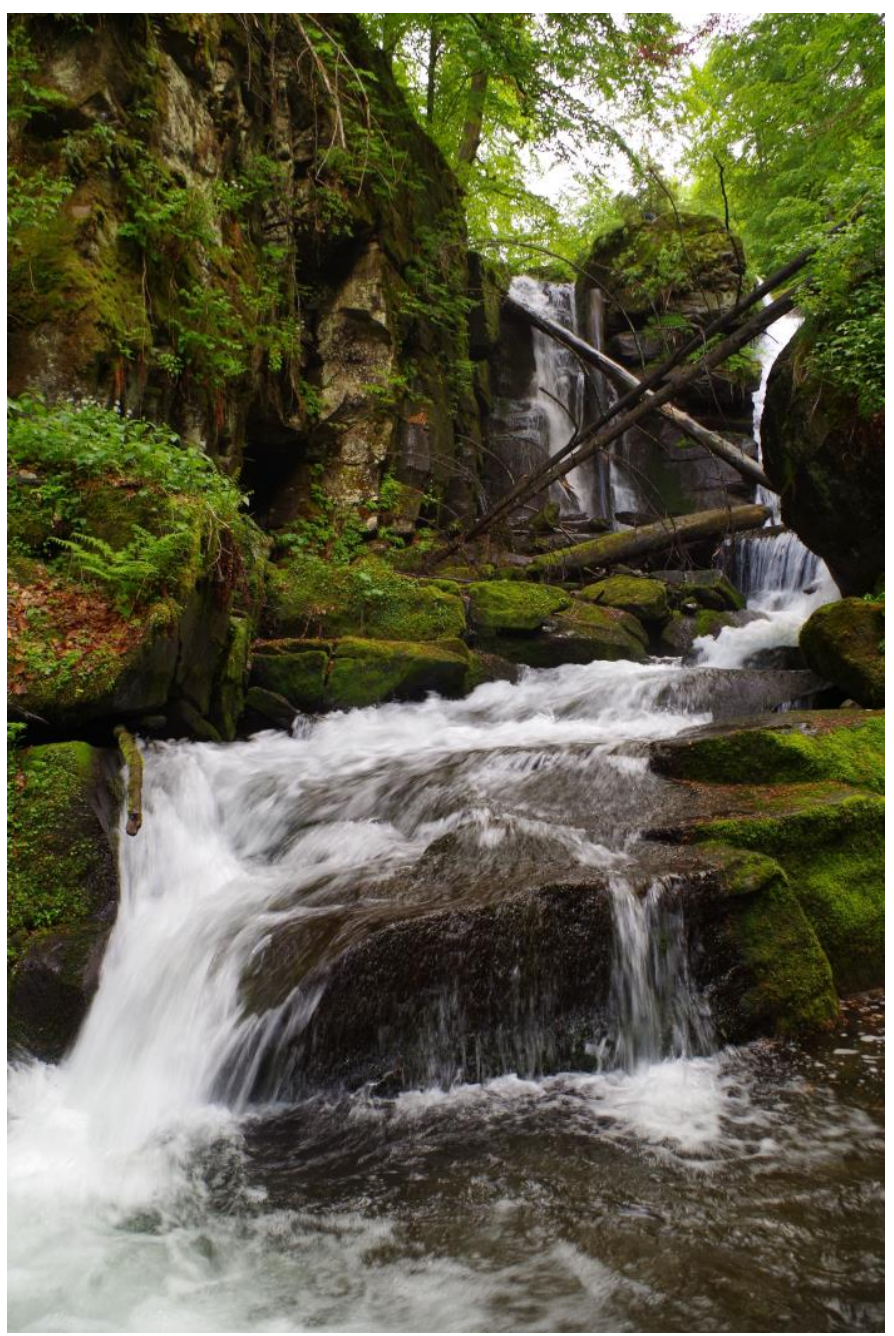

Fig 3: Sampling site No. 10: Vojvodina Waterfalls - Tur'ya Polyana. 
Results

\section{FAMILY BIBIONIDAE}

Bibio leucopterus (Meigen, 1804)

Material examined: Site No. 2, 27.v.2016, 1 ․

Distribution and remarks: Europe: Austria, Belgium, Czech Republic, Denmark, France, Germany, Great Britain, Hungary, Ireland, Italy, Netherlands, Northern Ireland, Poland, Slovakia, Sweden, Switzerland (Skartveit 2013). First record for Ukraine.

Bibio varipes Meigen, 1830

Material examined: Site No. 2, 27.v.2016, 1 ภ, 3 우우.

Distribution and remarks: Europe: Austria, Belgium, Czech Republic, Denmark, Finland, France (incl. Corsica), Germany, Great Britain, Ireland, Italy, Norway, Poland, Slovakia, Sweden, Switzerland (Skartveit 2013). First record for Ukraine.

\section{FAMILY BLEPHARICERIDAE}

\section{Liponeura cinerascens minor Bischoff, 1922}

Material examined: Site No. 10, 27.v.2016, 2 $ぇ$.

Distribution and remarks: Europe: Austria, Czech Republic, France, Germany, Italy, Liechtenstein, Poland, Romania, Slovakia, Slovenia, Switzerland (Zwick 2013a). First record for Ukraine.

\section{FAMILY DIXIDAE}

\section{Dixa submaculata Edwards, 1920}

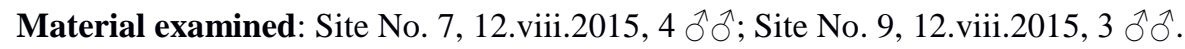

Distribution and remarks: Europe: Belgium, Denmark, France (incl. Corsica), Germany, Great Britain, Greece, Hungary, Ireland, Italy, Lithuania, Netherlands, Poland, Romania, Spain, Switzerland; Turkey, Armenia (Wagner 2013; Koç et al. 2006; Oboňa et al. 2017). Although no Dixidae are recorded for Ukraine in the Fauna Europea (Wagner 2013), in Koç et al. (2006) D. submaculata is mentioned from there. Questionable first record for Ukraine.

\section{Dixa puberula Loew, 1849}

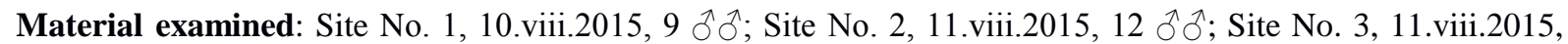

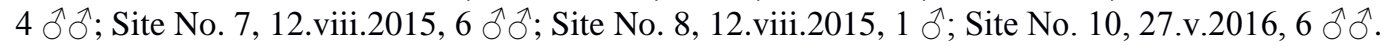

Distribution and remarks: Europe: Andorra, Austria, Belgium, Denmark, France (incl. Corsica), Germany, Great Britain, Greece, Hungary, Netherlands, Ireland, Italy (incl. Sicily), Poland, Romania, Switzerland; Armenia (Wagner 2013; Oboňa et al. 2017). First records for Ukraine.

\section{Dixa nebulosa Meigen, 1830}

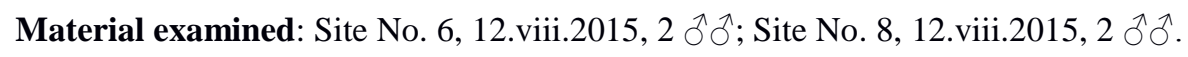

Distribution and remarks: Europe: Austria, Belgium, Denmark, Finland, France (incl. Corsica), Germany, Great Britain, Greece, Hungary, Ireland, Italy (incl. Sardinia, Sicily), Lithuania, Malta, Norway, Poland, Sweden, Switzerland, former Yugoslavia; Russia: North; Turkey; Tajikistan; Morocco (Wagner 2013; Koç et al. 2006; Ebejer 2000). First records for Ukraine. 


\section{FAMILY LIMONIIDAE}

Molophilus (Molophilus) terrayi Starý, 1992

Material examined: Site No. 10, 27.v.2016, 1 ภे.

Distribution and remarks: Known only from the type locality in Slovakia (Starý 1992). First record since original description, first record for Ukraine.

Elephantomyia (Elephantomyia) krivosheinae Savchenko, 1976

Material examined: Site No. 10, 27.v.2016, 1 q.

Distribution and remarks: Europe: Czech Republic, Finland, Hungary, Lithuania, Poland, Slovakia, Sweden, Switzerland; Russia: North, Central, East, West Siberia, Far East (Oosterbroek 2016). First record for Ukraine.

\section{FAMILY PEDICIIDAE}

Tricyphona (Tricyphona) contraria Bergroth, 1888

Material examined: Site No. 10, 27.v.2016, 1 กิ.

Distribution and remarks: Europe: Austria, Czech Republic, Germany, ?Italy, Slovakia, Switzerland; Russia: West (Oosterbroek 2016). First record for Ukraine.

\section{FAMILY PLATYPEZIDAE}

Agathomyia elegantula (Fallén, 1815)

Material examined: Site No. 6, 12.viii.2015, 1 ㅇ.

Distribution and remarks: Europe: Belgium, Czech Republic, Denmark, Finland, Germany, Great Britain, Hungary, Italy, Netherlands, Norway, Slovakia, Sweden, Switzerland; Russia: Central, East Palaearctic (Chandler 2013). First record for Ukraine.

\section{Callomyia amoena Meigen, 1824}

Material examined: Site No. 2, 10.viii.2015, 1 q.

Distribution and remarks: Europe: Austria, Belgium, Czech Republic, Denmark, Finland, France, Germany, Great Britain, Hungary, Ireland, Italy, Lithuania, Netherlands, Norway, Poland, Romania, Slovakia, Spain, Sweden, Switzerland; Russia: Central, East, North (Chandler 2013; Tkoč \& Roháček 2014). First record for Ukraine.

\section{Callomyia speciosa Meigen, 1824}

Material examined: Site No. 2, 10.viii.2015, 1 ㅇ.

Distribution and remarks: Europe: Andorra, Austria, Belgium, Czech Republic, Denmark, Finland, France, Germany, Great Britain, Greece, Hungary, Ireland, Italy, Lithuania, Netherlands, Norway, Poland, Portugal, Romania, Slovakia, Slovenia, Spain, Sweden, Switzerland; Israel; Turkey; Russia: Central, North, Caucasus (Chandler 2013; Tkoč \& Roháček 2014). First record for Ukraine. 


\section{FAMILY PTYCHOPTERIDAE}

\section{Ptychoptera (Paraptychoptera) longicauda (Tonnoir, 1919)}

Material examined: Site No. 4, 11.viii.2015, $1 \widehat{\delta}$.

Distribution and remarks: Europe: Austria, Belgium, Czech Republic, Denmark, Germany, Great Britain, Hungary, Netherlands, Poland, Slovakia, Slovenia, Sweden, Switzerland (Zwick 2013b). First record for Ukraine.

\section{FAMILY RHAGIONIDAE}

\section{Chrysopilus cristatus (Fabricius, 1775)}

Material examined: Site No. 4, 11.viii.2015, 2 के $\hat{\sigma}, 1$ +.

Distribution and remarks: Europe: Albania, Andorra, Austria, Belgium, Bosnia and Herzegovina, Bulgaria, Croatia, Czech Republic, Denmark, Finland, France, Germany, Great Britain, Hungary, Ireland, Italy, Lithuania, Luxembourg, Netherlands, Norway, Poland, Romania, Slovakia, Slovenia, Spain, Sweden, Switzerland, former Yugoslavia; Russia: Central, North, Northwest, South (Majer 2013). First record for Ukraine.

\section{Rhagio tringarius (Linnaeus, 1758)}

Material examined: Site No. 5, 12.viii.2015, 1 ○.

Distribution and remarks: Europe: Albania, Andorra, Austria, Belarus, Belgium, Bosnia and Herzegovina, Bulgaria, Croatia, Czech Republic, Denmark, Finland, France, Germany, Great Britain, Hungary, Ireland, Italy, Lithuania, Luxembourg, Netherlands, Norway, Romania, Russia, Slovakia, Slovenia, Spain, Sweden, Switzerland, former Yugoslavia; Russia: East, North, Northwest (Majer 2013). First record for Ukraine.

\section{Symphoromyia melaena (Meigen, 1820)}

Material examined: Site No. 4, 27.v.2016, 1 ठै.

Distribution and remarks: Europe: Austria, Czech Republic, France, Germany, Great Britain, Hungary, Italy, Romania, Slovakia; Russia: Northwest (Majer 2013). First record for Ukraine.

\section{Discussion}

Altogether 16 species of the dipteran families Bibionidae, Blephariceridae, Dixidae, Limoniidae, Pediciidae, Platypezidae, Ptychopteridae, and Rhagionidae collected in the Uzh River Basin from random and extensive sampling, are recorded as new to the fauna of Ukraine. Four species of the family Bibionidae were known to occur in Ukraine previous to this paper, viz. Bibio ferruginatus (Linnaeus, 1767), B. marci (Linnaeus, 1758), Dilophus febrilis (Linnaeus, 1758), and D. humeralis Zetterstedt 1850 (Skartveit 2013). The present records of Bibio leucopterus and B. varipes increase species richness of the family in Ukraine to six species. No records of the family Blephariceridae have so far been published from Ukraine (Zwick 2013a). Now Liponeura cinerascens minor is added to the fauna. The family Dixidae was represented in Ukraine by a questionable record of Dixa submaculata (Koç et al. 2006). The present paper reports three species from Ukraine, Dixa submaculata, D. puberula, and D. nebulosa. A total of 241 species of the family Limoniidae were previously known to occur in Ukraine (Oosterbroek 2016). The present records of Molophilus (M.) terrayi and Elephantomyia (E.) krivosheinae increase species richness of the family in Ukraine to 243 species. Moreover, the former species is here recorded for the first time since its original 
description. Altogether 29 species of the family Pediciidae were previously known to occur in Ukraine (Oosterbroek 2016). Tricyphona (T.) contraria increases the number to 30 species. Only two species of the family Platypezidae, Platypeza fasciata Meigen, 1804 and Protoclythia rufa Meigen, 1830, were previously known to occur in Ukraine (Chandler 2013). The present records of Agathomyia elegantula, Callomyia amoena, and C. speciosa increase species richness to five species. Four species of the family Ptychopteridae have so far been known from Ukraine, viz. Ptychoptera (Paraptychoptera) lacustris Meigen, 1830, $P$. (Ptychoptera) albimana (Fabricius, 1787), P. (P.) contaminata (Linnaeus, 1758), and P. (P.) scutellaris Meigen, 1818 (Zwick 2013b). P. (Paraptychoptera) longicauda increases the number to five species. Only three species of the family Rhagionidae were previously known to occur in Ukraine, viz. Chrysopilus nubecula (Fallen, 1814), C. splendidus (Meigen 1820), and Rhagio latipennis (Loew 1856) (Majer 2013). The present records of Chrysopilus cristatus, Rhagio tringarius, and Symphoromyia melaena increase species richness of the family Rhagionidae in Ukraine to six species.

Acknowledgements: This work was supported by the FAN (B) - Förderkreis für allgemeine Naturkunde (Biologie) in the framework of the project "Ephemeroptera, Plecoptera, Diptera biodiversity trip along the Uzh river, Ukraine". The study of J. S. was financially supported by the Ministry of Culture of the Czech Republic by institutional financing of long-term conceptual development of the research institution (the Silesian Museum, MK000100595), internal grant of the Silesian Museum No. IGS201706/2017. The work of J. O. was partially supported by the Slovak Research and Development Agency under contract No. SK-UA-2013-0023. The work of M. T. was supported by the Ministry of Culture of the Czech Republic (DKRVO 2017/13, National Museum, Prague, 00023272) and by the Institutional Research Support grant of the Charles University, Prague (SVV No. 260 434/2017).

\section{References}

Chandler P.J. (2001): The flat-footed flies (Diptera: Opetiidae and Platypezidae) of Europe. Fauna Entomologica Scandinavica.Vol. 36. Brill, Leiden, Boston, Köln. 276 pp.

- (2013): Fauna Europaea: Platypezidae. In: Pape T. \& Beuk P. (eds): Fauna Europaea: Diptera, Brachycera. Fauna Europaea version 2.6.2. <http://www.faunaeur.org >. (accessed 20.2.2017).

Disney R.H.L. (1999): British Dixidae (meniscus midges) and Thaumaleidae (trickle midges): keys with ecological notes. - Freshwater Biological Association Scientific Publication 56: 1-129.

Ebejer M.J. (2000): First records of Dixidae (Diptera, Nematocera) from Malta. - Central Mediterranean Naturalist 3(2): 43-45.

Haarto A. (2012): Suomen karvasääsket jamaasääsket (Diptera, Bibionidae ja Pleciidae) [Finnish March flies (Diptera, Bibionidae and Pleciidae)]. - w-album (12): 3-31.

Koç H., Wagner R. \& Özgül O. (2006): Contributions to the Dixidae (Insecta, Diptera) fauna of Turkey. Dipterological Research. November 173: 205-207.

Krivosheina N.P. (1969): Family Bibionidae. In: Bei-Bienko G.Y. (ed.): A Key to the Insects of the European Part of the USSR. Vol. 4, Part 1. Nauka, Leningrad, 433-442.

Majer J. (2013): Fauna Europaea: Rhagionidae. In: Pape T. \& Beuk P. (eds): Fauna Europaea: Diptera, Nematocera. Fauna Europaea version 2.6.2. 〈http://www.faunaeur.org>. (accessed 20.2.2017).

Oboňa J., Dvořák L., Haenni J-P., Manko P., Hrivniak L. \& Papyan L. (2017): New records of Diptera families Anisopodidae, Bibionidae, Dixidae, Ptychopteridae, and Scatopsidae from Armenia. - Spixiana 40: in press.

Oosterbroek P. (2016): Catalogue of the Craneflies of the World (Insecta, Diptera, Nematocera, Tipuloidea). <http://ccw.naturalis.nl>. (accessed 20.2.2017).

Rozkošný R. \& Spitzer K. (1965): Schnepfenfliegen (Diptera, Rhagionidae) in der Tschechoslowakei. - Acta entomologica bohemoslovaca 62: 340-368.

Skartveit J. (2013): Fauna Europaea: Bibionidae. In: Pape T. \& Beuk P. (eds): Fauna Europaea: Diptera, Nematocera. Fauna Europaea version 2.6.2. 〈http://www.faunaeur.org>. (accessed 20.2.2017).

Starý J. (1992): Three new species of the eriopterine Limoniidae from Czechoslovakia (Diptera). - Časopis Slezského Muzea Opava (A) 41: 105-112.

Tkoč M. \& Roháček J. (2014): Diversity, distribution and biology of Romanian flat-footed flies (Diptera, Opetiidae and Platypezidae) with taxonomic notes on Callomyia saibhira Chandler. - Zookeys 459: 95-118. 
Tuša I. (1992a): Keys to Liponeura (Diptera, Blephariceridae) of Czechoslovakia. Okresní vlastivědné muzeum, Šumperk, 17 pp.

- (1992b): Proudomilky - Liponeura Loew, 1844 (Diptera, Blephariceridae) Československa. [Net-winged midges - Liponeura Loew, 1844 (Diptera, Blephariceridae) of Czechoslovakia] - Časopis Slezského Muzea Opava (A) 41: 269-278.

Wagner R. (2013): Fauna Europaea: Dixidae. In: Pape T. \& Beuk P. (eds): Fauna Europaea: Diptera, Nematocera. Fauna Europaea version 2.6.2. 〈http://www.faunaeur.org>. (accessed 20.2.2017).

Zitek - Zwyrtek K. (1971): Czechoslovak species of the family Ptychopteridae (Diptera). - Acta Entomologica Bohemoslovaca 68: 416-426.

Zwick P. (2013a): Fauna Europaea: Blephariceridae. In: Pape T. \& Beuk P. (eds): Fauna Europaea: Diptera, Nematocera. Fauna Europaea version 2.6.2. <http://www.faunaeur.org>. (accessed 20.2.2017).

- (2013b): Fauna Europaea: Ptychopteridae. In: Pape T. \& Beuk P. (eds): Fauna Europaea: Diptera, Nematocera. Fauna Europaea version 2.6.2. <http://www.faunaeur.org>. (accessed 20.2.2017).

Authors' addresses: Jozef Oboňa*, Peter Manko \& Ruslan Mariychuk, Department of Ecology, Faculty of Humanities and Natural Sciences, University of Prešov, 17. novembra 1, SK-081 16 Prešov, Slovakia.

E-mail: obonaj@centrum.sk, ruslan.mariychuk@unipo.sk, mankope@gmail.com *corresponding author: obonaj@centrum.sk

Libor Dvořák, Municipal Museum Mariánské Lázně, Goethovo nám. 11, CZ-353 01

Mariánské Lázně, Czech Republic.

E-mail: lib.dvorak@seznam.cz

Jaroslav Starý, Neklanova 7, CZ-779 00 Olomouc-Nedvězí, Czech Republic and Silesian Museum, Nádražní okruh 31, CZ-746 01 Opava, Czech Republic.

E-mail: stary.cranefly@gmail.com

Michal Tkoč, Department of Entomology, National Museum, Cirkusová 1740, CZ-193 00 Praha 9 - Horní Počernice, Czech Republic and Department of Zoology, Faculty of Science, Charles University in Prague, Viničná 7, CZ-128 43 Praha 2, Czech Republic. E-mail: michaltkoc@gmail.com 